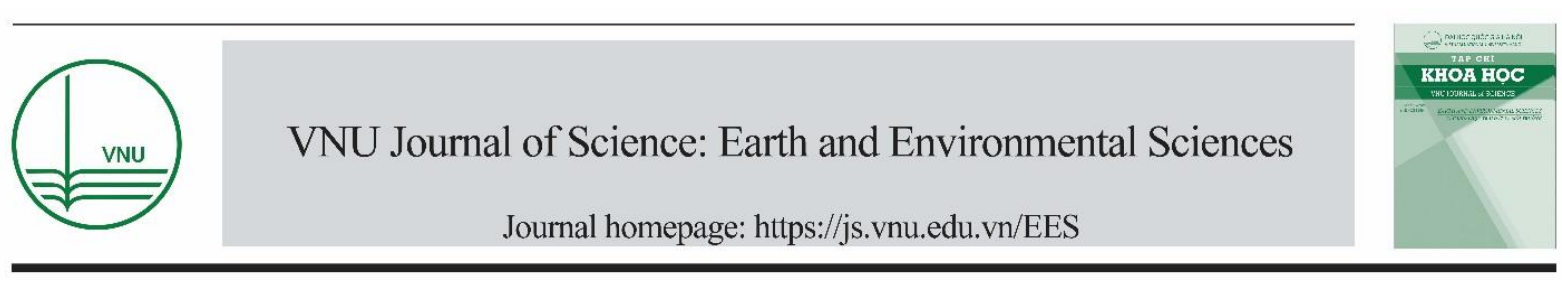

\title{
Original Article Application of Ferrate as Coagulant and Oxidant Alternative for Purifying Saigon River Water
}

\author{
Tran Tien Khoi ${ }^{1}$, Nguyen Dang Hoang Chuong ${ }^{2}$, Hoang Gia Phuc ${ }^{1}$, \\ Nguyen Thi Thuy ${ }^{3}$, Nguyen Nhat Huy ${ }^{2, *}$ \\ ${ }^{1}$ International University, Vietnam National University Ho Chi Minh City, \\ 6 Linh Trung, Thu Duc, Ho Chi Minh, Vietnam \\ ${ }^{2}$ Ho Chi Minh City University of Technology, Vietnam National University Ho Chi Minh City, \\ 268 Ly Thuong Kiet, Ward 14, Ho Chi Minh, Vietnam \\ ${ }^{3}$ Ho Chi Minh City University of Food Industry, 140 Le Trong Tan, Tay Thanh, Ho Chi Minh, Vietnam \\ Received 06 August 2019 \\ Revised 09 December 2019; Accepted 17 December 2019
}

\begin{abstract}
In this study, we aimed to use ferrate as an all-in-one alternative for the removal of chlorine-consumed compositions such as organic, color, turbidity, iron, and manganese in river water for water supply purposes. Ferrate $\left(\mathrm{FeO}_{4}{ }^{2-}\right)$ was simultaneously employed as coagulant and oxidant for purification of Saigon River water in order to reduce the formation of disinfection byproducts in the produced tap water. The Jartest was conducted using both ferrate for raw river water and poly-aluminum chloride (PAC) for chlorinated water to determine the optimum concentration of chemicals and $\mathrm{pH}$ values as well as comparing the effectiveness of ferrate and traditional coagulation with pre-chlorination technology for surface water purification. Results showed that ferrate could be used to remove organic compounds with high efficiency of $86.2 \%$ at $\mathrm{pH} 5-6$ and ferrate concentration of $16 \mathrm{mgFe} / \mathrm{L}$. Moreover, the removal efficiency for turbidity, color, and iron were at least $90 \%$, indicating that ferrate would be a very promising alternative for chlorine and $\mathrm{PAC}$ for water purification.
\end{abstract}

Keywords: ferrate, natural organic matters removal, water purification, DBPs control.

\section{Introduction}

Saigon River is the main source for tap water supply in Ho Chi Minh City, where water quality is degraded year by year due to the poor upstream pollution management [1]. For maintaining the tap water quality, more chlorine is using by Tan Hiep Water Treatment Plant (THWTP) in Ho Chi Minh City (Vietnam) for pre-oxidation of natural organic matters (NOMs), ammonia, iron, and manganese as well as to prevent algae growth in treatment units. This increasing use of chlorine of the plant could increase in disinfection by-products (DPBs)

\footnotetext{
* Corresponding author.

E-mail address: nnhuy@hcmut.edu.vn

https://doi.org/10.25073/2588-1094/vnuees.4425
} 
formation in tap water [2], which were found in tap water samples of Ho Chi Minh City [1]. During disinfection and chlorination processes, chlorine $\left(\mathrm{Cl}_{2}\right.$ gas) is dissolved, hydrolyzed, and reacted with NOMs as well as bromide ion in water to form trihalomethanes (THMs, a typical type of DBPs) [3-5]. The formation of THMs in water is dependent on chlorine concentration, concentration and property of NOMs, $\mathrm{pH}$, temperature, and bromide ion. Most of DPBs are harmful to human health while some are recognized as carcinogens [6,7]. The control of DBPs is mainly focused on the use of disinfectant and the removal of NOMs content in water by proper operation of water treatment plant and pollution control of water source. Methods for DPBs control and reduction include using alternative disinfectants (e.g. chloramine, chlorine dioxide, ozone, UV, and potassium permanganate), DPBs precursor removal (e.g., by enhanced coagulation with activated carbon (AC)/ozonation/nanofiltration, bio-filtration, ion exchange, AC adsorption, and membrane filtration), and removal of DBPs formed in water (e.g., by air stripping, reverse osmosis, AC adsorption, and photocatalysis) [8-10]. In case of Saigon River water treatment, DPB precursor removal could be the most effective method for the prevention of DPBs formation and looking for a multifunctional chemical that could remove both NOMs and other pollutants is particularly needed. On the other hand, ferrate $\left(\mathrm{FeO}_{4}{ }^{2-}\right)$ has attracted many attention because of its high oxidation ability and onsite supplying of ferric coagulant, which could be very potential as a green solution for surface water, ground water, and wastewater treatment [11-15]. Most of the studies focused on synthetic water sample for organics removal. There is very limited information on the use of ferrate for treatment of actual river water at supply water treatment plant as an alternative for pre-chlorination, algae growth prevention, oxidation, and coagulation- flocculation.

This study is aimed to use ferrate as an alternative chemical for purification of Saigon River water as input water for tap water supply in order to reduce the formation of DBPs. Effects of $\mathrm{pH}$ and ferrate concentration were investigated for obtaining the optimum operation condition. The performance of ferrate was also compared with those of traditional pre-oxidation with chlorine and subsequent coagulation with poly-aluminum chloride (PAC).

\section{Materials and Methods}

Saigon River water samples were taken at Hoa Phu Pumping station of THWTP (Ho Chi Minh City, Vietnam), preserved in a storage room at $4^{\circ} \mathrm{C}$, and used within 3 days. Before each experiment, the water sample with desire volume was let in ambient environment for increasing the temperature to $20^{\circ} \mathrm{C}$. For comparison purpose, the pre-chlorinated water samples at THWTP were also taken for traditional chemical coagulation test.

Solid ferrate was synthesized in the laboratory followed a previous published procedure using analytical grade chemicals [16,17], then stored in a desiccator, and used within 1 month. Other chemicals used for analysis are analytical grade while PAC is at industrial grade (same at the one is used at THWTP).

In this study, the optimum conditions of $\mathrm{pH}$ and ferrate concentration were obtained by using Jartest experiments with 5 beakers containing $1000 \mathrm{~mL}$ of water sample at $20^{\circ} \mathrm{C}$. Ferrate was then added with amounts of $4,8,12,16,20$ $\mathrm{mgFe} / \mathrm{L}$ and $\mathrm{pH}$ was adjusted from 5 to 9 by acid (for low $\mathrm{pH}$ ) or basic (for high $\mathrm{pH}$ ) solution [18]. The samples were then followed by rapid mixing at $180 \mathrm{rpm}$ for $2 \mathrm{~min}$ for reaction and coagulation, then slow mixing at $60 \mathrm{rpm}$ for $20 \mathrm{~min}$ for flocculation, and finally quiescent sedimentation for $30 \mathrm{~min}$. These contact/reaction times are typical for treatment of water at THWTP and other surface water treatment processes. The supernatant was then taken for water quality analysis. Performance of current coagulation technology at THWTP was investigated by using similar PAC as used in THWTP to coagulate pre-chlorinated water samples. To obtain optimum condition of $\mathrm{pH}$ (6-8) and PAC concentration $(5-25 \mathrm{mg} / \mathrm{L})$ in typical range of testing in THWTP, Jartest was also performed. 
Water quality parameters were analyzed at Environmental Analysis Laboratory (Faculty of Environment and Natural Resources, Ho Chi Minh City University of Technology). pH was measured using HI 98107 pH meter (Hanna Instruments) and turbidity by DR890 colorimeter (Hach Company). Color, iron, and manganese were analyzed using HI 83099 Spectrophotometer (Hanna Instruments). The concentration of natural organic matter (NOMs) was evaluated via Permanganate index $\left(\mathrm{COD}_{\mathrm{Mn}}\right)$, following the procedure given in ISO 8467:1993.

\section{Results and Discussion}

In order to compare the performance of ferrate and PAC for water purification, the coagulation, flocculation, and sedimentation times were kept at 2, 20, and $30 \mathrm{~min}$, respectively. Concentration of ferrate would have strong effect on the efficiency of raw river water treatment. As observed in Figure 1, the removal of turbidity reached highest efficiency of $95.2 \%$ at ferrate concentration of $8 \mathrm{mgFe} / \mathrm{L}$, where both lower and higher concentration reduced the removal efficiency. In contrast, the removal of NOMs (as $\mathrm{COD}_{\mathrm{Mn}}$ ) increased from 44.8 to $86.2 \%$ when ferrate concentration increased from 4 to $20 \mathrm{mgFe} / \mathrm{L}$. The removal of color reached highest efficiency of $94.4 \%$ at 16 $\mathrm{mgFe} / \mathrm{L}$ and around $90 \%$ in concentration range of $8-20 \mathrm{mgFe} / \mathrm{L}$. These results could be explained by the bifunctional of ferrate as a coagulant and an oxidant [12,14,16,17,19]. At concentration of $4 \mathrm{mgFe} / \mathrm{L}$, the coagulation efficiency of ferrate is limited as little flocs was observed during the experiment, thus affected the removal of turbidity. At $\mathrm{pH} \mathrm{5}$, when concentration increased to $8 \mathrm{mgFe} / \mathrm{L}$, the formation of $\mathrm{Fe}(\mathrm{OH})_{2}{ }^{+}$and $\mathrm{Fe}(\mathrm{OH})^{2+}$ could neutralize the colloids with negative charge in the solution and promote the coagulation flocculation. At higher concentration, the colloid charge became positive and therefore decreased the coagulation efficiency. However, higher concentration had the benefit of oxidation under acidic condition, and more ferrate means more oxidant for removal of NOMs and colored compounds, proven by the increase of NOMs and color removal efficiency with the increase of ferrate concentration.

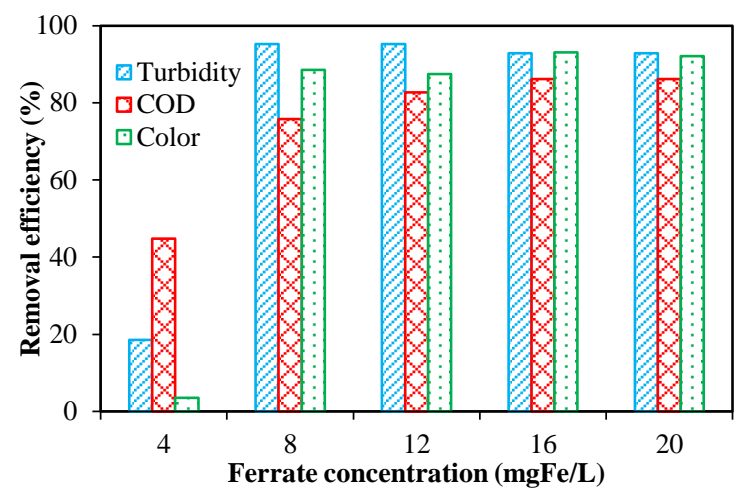

Fig. 1. Effect of ferrate concentration on turbidity, NOMs (as COD), and color removal efficiency (at pH 5).

Figure 2 illustrates the effect of $\mathrm{pH}$ on the removal of turbidity, NOMs, and color in raw river water. Results showed that the performance of ferrate strongly depended on $\mathrm{pH}$ of the environment, which determines the decay rate of ferrate as well as its characteristic and its role mainly as coagulant or oxidant. For turbidity, the removal efficiency reached the highest value of $97.6 \%$ at $\mathrm{pH} 6$ and concentration of $8 \mathrm{mgFe} / \mathrm{L}$ and remained stable at higher concentrations. This proven the relatively stable coagulation ability of ferrate at $\mathrm{pH} 6$, which involving both colloid charge neutralization and sweep flocculation by amorphous iron hydroxide precipitates [14]. The removal of NOMs and color at $\mathrm{pH} 6$ was similar to those at $\mathrm{pH} 5$, indicating the effect of both coagulation (i.e. predominant at $\mathrm{pH}$ 6) and oxidation (i.e. favorable at $\mathrm{pH}$ 5) capability of ferrate. Moreover, the removal efficiency of turbidity, NOMs, and color mostly decreased when $\mathrm{pH}$ increased from 6 to 7,8 , and 9 due to the decrease of ferrate oxidation ability and slow decomposition of ferrate at neutral or basic condition. High ferrate concentration at high $\mathrm{pH}$ environment also produces more precipitates which could even increase the color and turbidity of water. And the mechanism mainly depended 
on the sweep flocculation at high ferrate concentration for relative stable colloid at neutral or high $\mathrm{pH}$ value. It can be concluded that ferrate have both oxidation and coagulation functions, but these two abilities were not optimized at the same $\mathrm{pH}$ condition. Therefore, $\mathrm{pH} 6$ was chosen as optimum condition due to the high removal efficiency of turbidity, NOMs, and color in water, as well as less chemical consumption for neutralization.
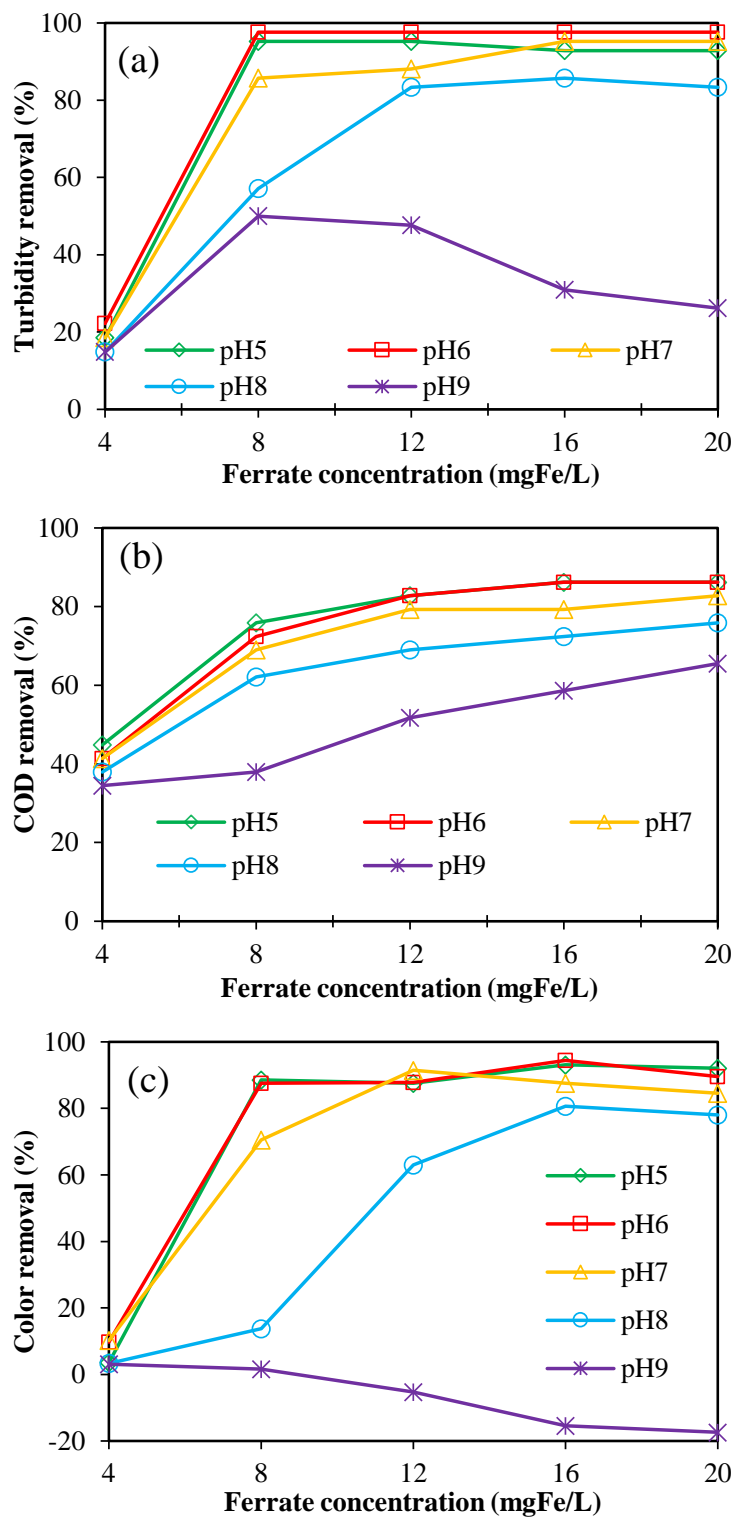

Fig. 2. Effect of $\mathrm{pH}$ and ferrate concentration on (a) turbidity, (b) NOMs, and (c) color removal.
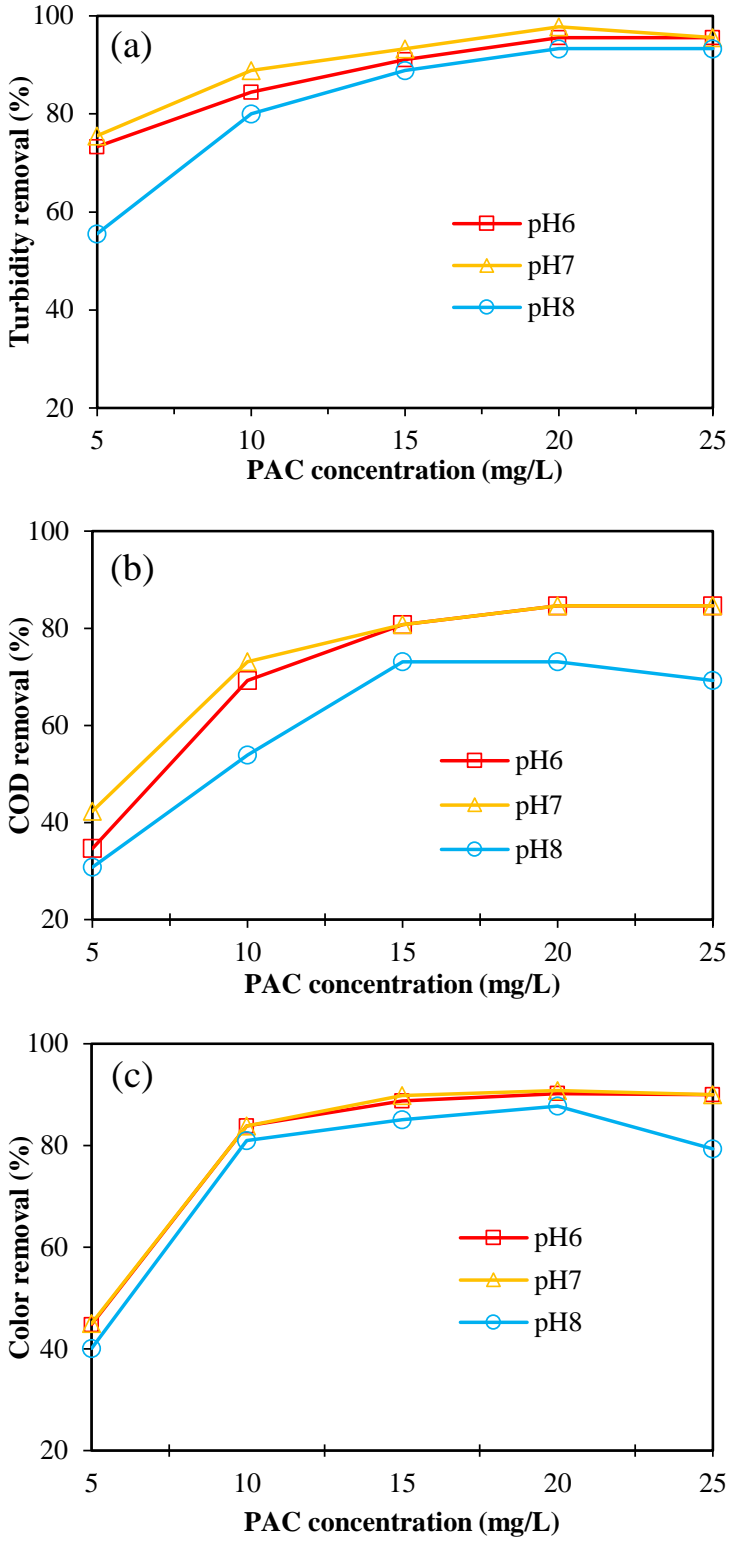

Fig. 3. Effect of $\mathrm{pH}$ and PAC concentration on (a) turbidity, (b) NOMs, and (c) color removal.

In comparison with ferrate, the experiments using PAC at different concentrations (5-25 $\mathrm{mg} / \mathrm{L})$ and $\mathrm{pH}(6-8)$ were conducted with prechlorinated water sample from THWTP. Results in Figure 3 reveal similar trends in the removal of turbidity, NOMs, and color regardless $\mathrm{pH}$ value, possibly because of the only coagulation function of PAC. The highest removal efficiencies were $97.8,84.6$, and $87.7 \%$ for 
turbidity, NOMs, and color, respectively, at $\mathrm{pH}$ 7 and PAC concentration of $20 \mathrm{mg} / \mathrm{L}$. These high removal efficiencies prove that the prechlorination step has enhancement effect on the removal of NOMs and color via oxidation and precipitation of dissolved contaminants such as iron and manganese by chlorine. In addition, the excess use of PAC showed insignificant negative effect on turbidity and color removal as ferrate. However, ferrate was superior in terms of NOMs removal since it provided the removal efficiency of $86.2 \%$ as compared to the efficiency of $84.6 \%$ achieved by the combination of pre-chlorination and $\mathrm{PAC}$ at $\mathrm{pH} 6-7$ and PAC concentration of $20 \mathrm{mg} / \mathrm{L}$. This showed a very potential application of ferrate as oxidant and coagulant for practical water treatment which could reduce the formation of DBPs while maintain high treatment efficiency of the water treatment plant.

Since $\mathrm{Fe}^{3+}$ is a product of ferrate treatment, iron removal efficiency using ferrate and PAC was investigated to find either ferrate provide negative or positive effect on iron removal. At a low concentration of $4 \mathrm{mgFe} / \mathrm{L}$, ferrate was not only unable to remove iron in raw water sample (initial concentration of $0.8 \mathrm{mg} / \mathrm{L}$ ) but also increased iron content in the treated water (2.95 $-3.30 \mathrm{mg} / \mathrm{L}$ in $\mathrm{pH}$ range of $5-9$ ), which did not meet the limit of National technical regulation on drinking water quality (QCVN 01:2009/BYT, $0.3 \mathrm{mg} / \mathrm{L}$ ). With the increase of ferrate concentration, iron removal was enhanced, as can be seen from Figure 4. It was also clear that increase of $\mathrm{pH}$ value from $5-9$ resulted in the decrease of iron removal efficiency. This trend can be explained by the low decay ability of ferrate which resulted in high iron content in water sample. However, with the increase of ferrate concentration, the removal of iron was significantly improved and reached the highest efficiency of $96.4 \%$ at concentration of 20 $\mathrm{mgFe} / \mathrm{L}$ and $\mathrm{pH} 5$ due to the strong oxidation of ferrate under acidic condition. The iron removal was also tested using PAC for pre-chlorinated water with a high removal efficiency of $98.8 \%$ at PAC concentration of $25 \mathrm{mg} / \mathrm{L}$ due to the coagulation enhancement via oxidation of iron by chlorine. Although the efficiency was not high as current technology of pre-oxidation by chlorine and coagulation by PAC, ferrate still have high ability to removal total iron in water with suitable concentration and $\mathrm{pH}$.
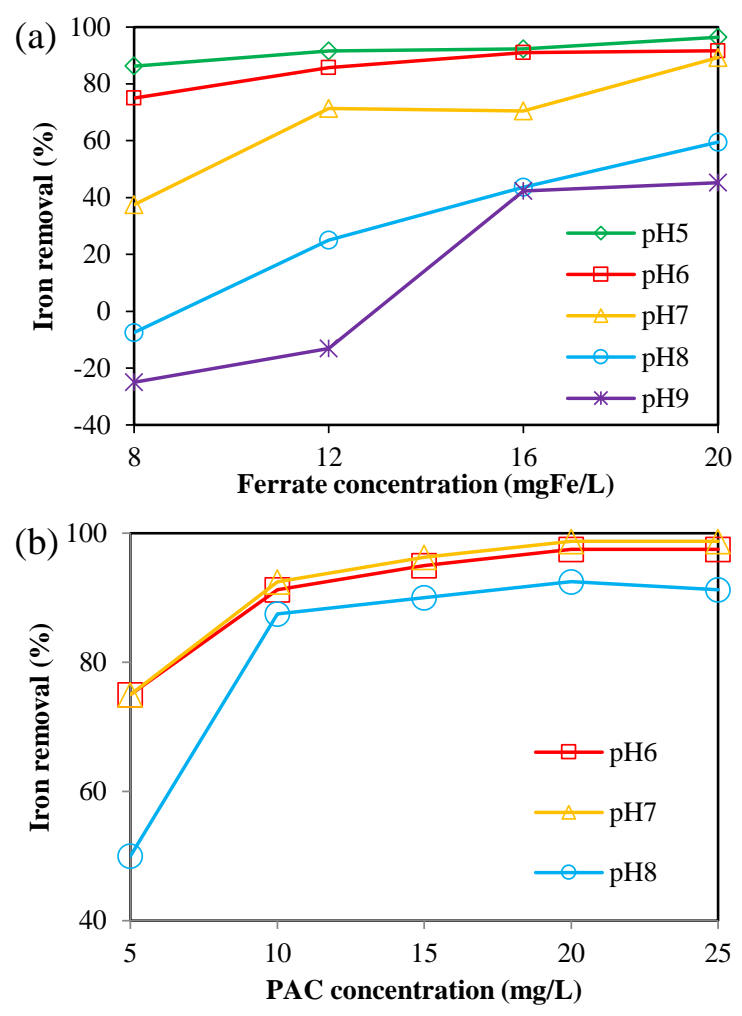

Fig. 4. Effect of $\mathrm{pH}$ and concentration on iron removal using (a) ferrate and (b) PAC.

Manganese usually co-exists with iron in organic colloidal form in surface water. The removal of manganese requires oxidation of dissolved $\mathrm{Mn}(\mathrm{II})$ species to $\mathrm{Mn}(\mathrm{IV})$ precipitates, which is done by chlorine oxidation in THWTP. In this study, ferrate was applied as alternative to remove manganese and the results are presented in Figure 5. As can be seen, a relative stable removal efficiency of manganese was achieved at around 50\% in a wide range of $\mathrm{pH}$ and ferrate concentration. Actually, manganese concentrations before $(0.2 \mathrm{mg} / \mathrm{L})$ and after treatment $(<0.1 \mathrm{mg} / \mathrm{L})$ were low and both met the standard (0.3 mg/L, QCVN 01:2009/BYT). These indicate the less dependence of manganese removal on coagulation- flocculation 
by ferrate. This low efficiency also implies that manganese is more stable and harder to be oxidized and hydrolyzed than iron under the tested condition.

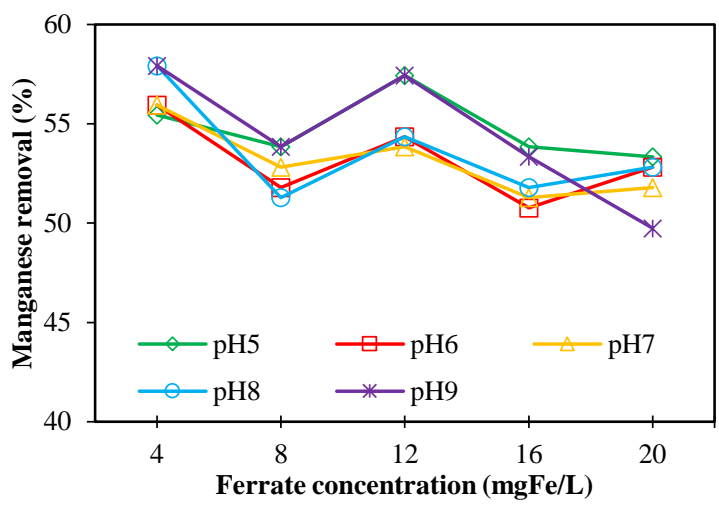

Fig. 5. Effect of $\mathrm{pH}$ and concentration on manganese removal using ferrate.

\section{Conclusion}

The use of ferrate could significantly reduce the formation of DBPs due to the reduction of both NOMs and chlorine consumption during the purification of Saigon River water as input water for water supply. Experiment results showed that ferrate is very potential and effective for river water purification in terms of turbidity, NOMs, color, iron, and manganese removal. Both $\mathrm{pH}$ and ferrate concentration had strong effect on the performance of ferrate for water treatment. Ferrate is more effective under acidic condition (i.e. $\mathrm{pH}$ range of 5-6) due to its both roles as oxidant and coagulant. The suitable $\mathrm{pH}$ is at 6 while ferrate concentration could be chosen based on the purification purposes (e.g. low concentration of $8 \mathrm{mg} / \mathrm{L}$ for turbidity and maybe higher concentration up to $16 \mathrm{mgFe} / \mathrm{L}$ for NOMs removal). In some conditions, ferrate is not as a good coagulant as PAC but the removal efficiency using ferrate was higher or competitive with pre-chlorination and coagulation due to its oxidation property. Future works should focus on the mechanism of iron and manganese removal in river water purification as well as the formation/reduction of DBPs

\section{References}

[1] V.N. Trang, L.D. Phuong, N.P. Dan, B.X. Thanh, C. Visvanathan, Assessment on the trihalomethanes formation potential of Tan Hiep Water Treatment Plant, J Water Sustain 2 (2012) 43-53. https://doi.org/10.11912/jws.2.1.43-53.

[2] R. Sadiq, M.J. Rodriguez, Disinfection byproducts (DBPs) in drinking water and predictive models for their occurrence: a review, Sci. Total Environ. 321 (2004) 21-46. https://doi.org/10. 1016/j.scitotenv.2003.05.001.

[3] S. Chowdhury, P. Champagne, P.J. McLellan, Models for predicting disinfection byproduct (DBP) formation in drinking waters: a chronological review, Sci. Total Environ. 407 (2009) 4189-4206. https://doi.org/10.1016/j.scito tenv.2009.04.006.

[4] T. Bond, J. Huang, M.R. Templeton, N. Graham, Occurrence and control of nitrogenous disinfection by-products in drinking water - A review, Water Res. 45 (2011) 4341-4354. http://dx.doi.org/10.1016/j.watres.2011.05.034.

[5] S.D. Richardson, M.J. Plewa, E.D. Wagner, R. Schoeny, D.M. DeMarini, Occurrence, genotoxicity, and carcinogenicity of regulated and emerging disinfection by-products in drinking water: a review and roadmap for research, Mutation Research/Reviews in Mutation Research 636 (2007) 178-242. https://doi.org/10.1016/j.mrr ev.2007.09.001

[6] E. Agus, N. Voutchkov, D.L. Sedlak, Disinfection by-products and their potential impact on the quality of water produced by desalination systems: a literature review, Desalination 237 (2009) 214237. https://doi.org/10.1016/j.desal.2007.11.059.

[7] C.G. Graves, G.M. Matanoski, R.G. Tardiff, Weight of evidence for an association between adverse reproductive and developmental effects and exposure to disinfection by-products: a critical review, Regul. Toxicol. Pharmacol. 34 (2001) 103-124. https://doi.org/10.1006/rtph.2001.1494.

[8] A. Matilainen, M. Vepsäläinen, M. Sillanpää, Natural organic matter removal by coagulation during drinking water treatment: A review, Adv. Colloid Interface Sci. 159 (2010) 189-197. http://dx.doi.org/10.1016/j.cis.2010.06.007.

[9] T. Chaiket, P.C. Singer, A. Miles, M. Moran, C. Pallotta, Effectiveness of coagulation, ozonation, and biofiltration in controlling DBPs, Journal (American Water Works Association) 94 (2002) 
81-95. https://doi.org/10.1002/j.1551-8833.2002. tb10251.x

[10] A. Matilainen, M. Sillanpää, Removal of natural organic matter from drinking water by advanced oxidation processes, Chemosphere 80 (2010) 351365. http://dx.doi.org/10.1016/j.chemosphere. 2010.04.067.

[11] K. Prabhat Rai, J. Lee, S.K. Kailasa, E.E. Kwon, Y.F. Tsang, Y.S. Ok, K.-H. Kim, A critical review of ferrate(VI)-based remediation of soil and groundwater, Environ. Res. 160 (2018) 420-448. https://doi.org/10.1016/j.envres.2017.10.016.

[12] A. Talaiekhozani, M.R. Talaei, S. Rezania, An overview on production and application of ferrate (VI) for chemical oxidation, coagulation and disinfection of water and wastewater, Journal of Environmental Chemical Engineering 5 (2017) 1828-1842. https://doi.org/10.1016/j.jece.2017. 03.025 .

[13] V.K. Sharma, Potassium ferrate(VI): an environmentally friendly oxidant, Adv. Environ. Res. 6 (2002) 143-156. https://doi.org/10.1016/ S1093-0191(01)00119-8.

[14] J.-Q. Jiang, B. Lloyd, Progress in the development and use of ferrate(VI) salt as an oxidant and coagulant for water and wastewater treatment,
Water Res. 36 (2002) 1397-1408. https://doi.org/ 10.1016/S0043-1354(01)00358-X

[15] D. Ghernaout, M.W. Naceur, Ferrate(VI): In situ generation and water treatment - A review, Desalination and Water Treatment 30 (2011) 319332. https://doi.org/10.5004/dwt.2011.2217.

[16] K.T. Tien, N. Graham, J.-Q. Jiang, Evaluating the coagulation performance of ferrate: A preliminary study, ACS Symp. Ser 985 (2008) 292-305. https://doi.org/10.1021/bk-2008-0985.ch017.

[17] N. Graham, T. Khoi, J.-Q. Jiang, Oxidation and coagulation of humic substances by potassium ferrate, Water Sci. Technol. 62 (2010) 929-936. https://doi.org/10.2166/wst.2010.369.

[18] J.-Q. Jiang, S. Wang, A. Panagoulopoulos, Comparative performance of potassium ferrate (VI) in drinking water and sewage treatment, Proceedings of the 9th International Conference on Environmental Science and Technology, Rhodes Island, Greece (2005) 1-3. https://doi.org/ 10.1080/19443994.2014.938303.

[19] V.K. Sharma, R. Zboril, R.S. Varma, Ferrates: Greener Oxidants with Multimodal Action in Water Treatment Technologies, Acc. Chem. Res. 48 (2015) 182-191. https://doi.org/10.1021/ar 5004219 